\title{
Definição do direito internacional privado
}

\author{
SUMMARIO \\ $\$ 10$ A sociedade e o direito. \\ $\S 20$ Phases principaes da evolução da sociedade \\ $\$ 3 .^{\circ}$ Phases parallelas da evolução do direito. \\ $\$ 4 .^{\circ}$ Existencia da sociedade internacional \\ $\S 5 .^{\circ}$ Existencia do direito internacional \\ $\$ 6 .^{\circ}$ Divisão do direito internacional em publico e \\ privado. \\ $\$ 7.0$ Definição do direito internacional privado

$$
\$ 10^{\circ}
$$

\section{A sociedade $\mathrm{e}$ o direito}

Os phenomenos sociaes mantêm entre si relações muito intimas. Penetram-se mutuamente.

Constitúem um todo de elementos interdependentes, que se modificam reciprocamente. O organismo social evolve-se em seu conjuncto e simultaneamente em cada uma de suas partes. As manifestações da actividade social se correspondem proporcionadamente. Influem-se reciprocamente, adaptam-se e readaptam-se umas ás outras, equilibram-se e integram-se em um todo organico e harmonico, de partes coherentes.

Os phenomenos juridicos, que formam um dos grupos dos phenomenos sociaes, estão intimamente ligados aos outros phenomenos sociaes. Todos têm um desenvolvimento parallelo e contemporaneo.

Marcham pari passu, connexos, unidos, presos pelo consensus ou entrosamento que os unifica e integra no grande todo, na complexa realidade social. 
Assim, as normas juridicas de um povo prendemse ás condições da vida individual e social desse povo, reflectindo-lhe as qualidades e medindo-lhe o gráu de civilização. O direito é um aspecto da sociedade. (1)

$$
\S 2 .^{\circ}
$$

\section{Phases principaes da evolução da Sociedade}

Posto que o processo evolutivo seja continuo, lento e gradual (2), póde-se todavia dizer, tendo em vista as transformações das ideias directoras do seu movimento, que a sociedade tem atravessado tres phases capitaes; a saber:

a) a phase do grupo patriarchal,

b) a phase da cidade e

c) a phase do estado, tambem denominadas

a) phase oriental,

b) phase classica e

c) phase moderna.

Depois de passar por essas tres phases percorridas por sua marcha evolutiva, tem a sociedade entrádo hoje francamente em uma quarta phase, que é

d) a phase da sociedade internacional.

Esta phase, que tambem se póde dizer contemporanea, representa a ultima formula da sociabilidade humana. A solidariedade humana, que a principio circumscrevia-se aos limites acanhados do primitivo grupo patriarchal, cimentada nos vinculos da consanguinidade, alargou-se na cidade classica, Polis grega e Civitas romana, calcada nos vinculos da contiguidade local.

Ampliou-se ainda no estado moderno. E universalizou-se na sociedade mundial, extendendo-se á humanidade inteira, fazendo de toda a terra a patria commum de todos. (3)

(1) Conf. meus Ensaios de philosophia do diveito, $\$ \S 4.0$ e 68.

(2) Conf. meus Ensaios citados, indice alphabetico, v. evolução.

(3) Meus Ensaios citados, $\$ \S 5.0$ e 68. 


\section{$\S 3 .^{\circ}$}

\section{Phases parallelas da evolução do direito}

A' vista do exposto no $\S 1 .^{\circ}$, que põe em destaque o consensus existente entre os phenomenos sociaes e, pois, entre o direito e as demais manifestações da actividade social, é de concluir que a evolução juridica deve correr pari passu ao lado da evolução da sociedade em seu conjuncto.

$E$ de facto assim é, conforme nos attesta a observação da vida social, desde seus primordios até seu estadio actual.

Dest'arte, tem o direito, por seu turno, atravessado as phases:

a) do grupo patriarchal,

b) da cidade $\mathrm{e}$

c) do estado,

e ora se acha, com a sociedade, na sua

d) phase mundial.

Foi acanhado e simples na phase oriental.

Cresceu na phase classica. Cresceu mais ainda na phase moderna. Universaliza-se hoje, na phase internacional ou mundial.

\section{$\S 4 .^{\circ}$}

\section{Existencia da sociedade imtermacional}

\section{PREVISÃO ESTOICA}

Os estoicos, os mais puros e directos precursores do christianismo, presentiram claramente a organização da republica universal ou estado mundial (Weltstaat).

Consideravam-se membros da humanidade, cidadãos do mundo inteiro, e falavam frequentemente da Civitas omnium maxima. Universus civitas est communis; civis sum totius mundi, dizia o genial Marco Aurelio. (4)

(4) Consultem-se meus Ensaios citados, $§ 51$. 


\section{SUA REALIZAÇÃO}

O sonho estoico está-se realizando em nossos dias. O grande organismo mundial, expressão do maximum da sociabilidade humana, integra-se e consolida-se dia a dia, deante de nossos olhos. O commercio mundial; os meios de communicação mundial; a immigração, o telegrapho e mil outros factores trabalham incessantemente na sua elaboração, estabelecendolhe a estructura e definindo-lhe as funcções leviathanicas. Fervet opus. O homo homini lupus, de Hobbes, está hoje completamente substituido pelo conceito contrario, que se póde expressar pelas palavras -Homo homini amicus.

A penetração reciproca dos povos se faz sentír em todas as espheras da actividade humana. E em qualquer ponto da terra, onde o homem actual se ache, encontrará sentimentos e ideias similhantes aos seus. A communhão mundial de cultura surgiu ao lado da communhão mundial de interesses, prendendo todos os homens e todos os povos num consensus universal de actividades interdependentes e coherentemente coordenadas. nidade.

Todos têm hoje uma patria commum: a huma-

A existencia da sociedade internacional, assim por tudo attestada e por todos sentida, é indubitavelmente um facto consummado, que ninguem póde negar.

\section{$\$ 50^{\circ}$}

\section{Existencia do direito imtermacional}

Como o homem só póde viver e desenvolver-se na sociedade, e esta só póde subsistir e desenvolver-se, medeante a restricção de actividade de suas unidades, conforme os ensinamentos da sociologia, claro é que o facto da existencia da sociedade mundial implica a existencia do direito correlativo, isto é, de um direito mundial (Weltrecht). 
Quem diz sociedade mundial ou internacional tem dito direito mundial ou internacional. (5)

Sociedade e direito são termos correlativos, como o são pae e filho, todo e parte, superior e inferior, justo e injusto.

São termos que se implicam; que se presuppõem mutuamente. Não se póde conceber um delles, sem o outro. (6)

$$
\S 6^{\circ}
$$

\section{Divisão do direito internacional em publico o privado}

\section{DUPLO ASPECTO DO DIREITO}

Em todo e qualquer dos momentos historicos da existencia da sociedade, tem o direito dois aspectos:

a) publico $t$

b) privado.

Sob o primeiro aspecto, é elle a regulamentação da actividade da sociedade. Sob o segundo, a regulamentação da actividade do individuo.

Os romanos foram os primeiros a perceber essa distincção, donde decorre a divisão do direito em dois grandes ramos:

a) direito publico e

b) direito privado,

que os mesmos romanos assim definiam:

Pubblicum jus est quod ad statum rei romanae spectat, privatum quod ad singulorum utilitatem. privatim.

Sunt enim quaedam publicè utilia, quaedam

(5) Convém consultar os Ensaios citados, $\$ \$ 10^{\circ}, 4 .^{\circ}, 6 .^{\circ}, 67$ e outros indicados no indice alphabetico, $v$ direito; Bevilacqua, Principios de direito internacional privado, $\$ 12$; Pillet, Principes de droit international privé, \$ $3 .^{\circ}$; Windscheid, Lehrbuch des Pandektenrechts, $§ 34$.

(6) Spencer, As bases da moral (The data or ethics), $\S 10^{\circ}$ 
São dois conceitos correlativos. Coexistem em todas as phases da evolução juridica.

Como o individuo presuppõe a sociedade, e a sociedade presuppõe o individuo, os dois aspectos do direito tambem se presuppõem.

\section{CONCEPCৃ̃̃O SUBJECTIVA E REALIDADE OBJECTIVA}

Mas convém noiar que esta divisão, nitida e clara na doutrina, constitúe uma concepção subjectiva, a que não corresponde, no mundo objectivo, uma linha separativa assim nitida e clara.

O direito, em qualquer dos referidos aspectos, respeita simultaneamente ao individuo e á sociedade, predominando ora um, ora outro desses aspectos; ora o elemento publico, ora o privado ou particular ou individual. Esta predominancia é que caracteriza, em cada caso concreto, a natureza do direito, dando-lhe a feição de publico ou de privado.

Direito publico é o que concerne principalmente ao estado.

Direito privado é o que concerne principalmente ao individuo. (7)

\section{BIPARTIÇÃO DO DIREITO INTERNACIONAL}

Do expendido, decorre logicamente a bipartição do direito internacional em :

a) direito internacional publico e

b) direito internacional privado.

O primeiro é o conjuncto organico das condições de vida e desenvolvimento dos estados e da sociedade mundial por elles constituida, dependentes da vontade humana e garantidas, ou que o devem ser, pela força coercitiva do poder publico.

O segundo é o que se verá no $\S$ immediato.

(7) Meus Ensaios citados, $\$ 121$, pags. 752-3.

(8) Meus Ensaios citados, $\$ 121$, pag. 745. 


\section{$\S 7 .^{\circ}$}

\section{Definição do direito internacional privado} guinte :

O conceito supremo do direito em geral é o se-

Direito é o conjuncto organico das condições de vida e desenvolvimento do individuo e da sociedade, dependentes da vontade humana e garantidas, ou que o derem ser, pela força coercitiva do poder publico.

Esta definição, a mais satisfatoria que encontrei em vinte annos de investigação juridica, é do dr. Pedro Lessa.

Adoptei-a e consignei-a no $\S 121$ dos meus Ensaios de philosophia do direito (pag. 745) que, pódese dizer, constitúem um commentario da correcta e profunda definição, a qual concretiza os ultimos progressos do pensamento juridico.

Cada pensamento implica um systema inteiro de pensamentos, diz Spencer (Primeiros principios, $\S 39$ ). Esta definição suprema do direito implica um systema inteiro de pensamentos juridicos: resume, em miniatura, todo o systema do direito, scientificamente concebido.

2. DEFINIC̣AO DO DIREITO INTERNACIONAL PRIVADO

$E^{\prime}$ o conjuncto organico das condiçoes de vida e desenvolvimento do individuo, como cidadão mundial, dependentes da vontade humana e garantidas, ou que o devem ser, pela força coercitiva do poder publico.

No direito internacional privado, o sujeito do direito é o individuo, civis totius mundi, ao passo que, no direito internacional publico, é o estado, como uni- 
dade da sociedade internacional, e, já se póde ir dizendo, esta mesma sociedade.

Innumeras são as definições, que do direito internacional privado têm dado os escriptores. Todas ellas, porém, a despeito de sua variedade infinda, redundam no conceito expresso na definição que acaba de ser dada. E nenhuma dellas o exprime com a precisão e profundeza que se notam na definição que adopto.

Todavia, concorrem, de modo notavel, para precisar melhor o conceito desse direito. Reproduzir algumas dellas será demonstrar este asserto.

\section{DEFINIÇÃO DE ASSER}

Direito internacional privado é o conjuncto dos principios que determinam a lei applicavel ás relaçôes juridicas entre pessôas pertencentes a estados diferentes, aos actos realizados em paizes extrangeiros e, emfim, a a todos os casos, em que se haja de fazer applicaçấo da lei de um estado no territorio de outro estado. (9)

4. DEFINIÇĀO DE PRADIER

Direito internacional privado é o conjuncto das regras, segundo as quaes se resolvem os conflictos entre o direito privado das diversas nações. (10)

5. DEFINIÇÃO DE BEVILACQUA

$E^{\prime}$ o conjuncto de preceitos reguladores das relações de ordem privadu da sociedade internacional. (11)

(9) Asser, Éléments de droit international privé, ou Du conflit des lois. n. 1.

(10) Pradier, Traducção do Direito internacional privado, de Fiore, pag. 3 , nota 2.

(11) Bevilacqua, Prinipios de direito internacional privado, $\S 11^{\circ}$ 


\section{CONFLICTOS DE LEIS}

Convém advertir que as definições de direito internacional privado, que fazem referencia ao conflicto de leis de differentes estados, reflectem um estadio da evolução deste direito, que se deve considerar já passado.

O objecto deste, aliás recentissimo, ramo de direito, não é propriamente resolver conflictos de direito privado entre as legislações dos differentes estados, mas antes regular a actividade do cidadão mundial, restringindo-lhe a respectiva esphera a bem da coexistencia organica e harmonica de todos os individuos no organismo humanitario ou sociedade internacional.

7. ASPECTOS, SOB QUE O INDIVIDUO ESTÁ SUJEITO Á LEI

Sob tres aspectos, está o individuo sujeito á lei:

a) o da sua pessôa,

b) o de seus bens,

c) o de seus actos.

O primeiro envolve as questões attinentes ao estado, condição e capacidade dà pessôa.

O segundo, as questões de acquisição, uso, goso e disposição dos bens. dos actos.

O terceiro, as questões de fórma, effeitos e prova

8. OBJECTO DO DIREITO INTERNACIONAL PRIVADO

E fixar as normas attinentes:

a) aos extrangeiros considerados uti singuli; trangeiro;

b) aos nacionaes, quando estiverem em paiz ex-

c) aos bens do extrangeiro sitos no estado; geiro, e

d) aos bens do nacional sitos em paiz extran-

e) aos actos, de quem quer que seja, realizados em um paiz, mas que devem produzir seus effeitos em outro paiz. 
9. O DIREITO INTERNACIONAL PRIVADO E UMA READAPTAÇAO

Póde-se dizer que este direito não é um direito novo, mas o mesmo direito antigo, ora readaptado ás condições da vida individual e social, transformadas pela formação da sociedade mundial.

O presente é o passado adaptado ás condições do momento, em que vivemos. $\mathrm{O}$ homem de hoje é o homem de hontem. A sociedade de hoje é a socieclade de hontem. O direito de hoje é o direito de hontem, modificado pela transformação das condições da vida individual e social. Natura non facit saltus.

O presente é sempre uma readaptação do passado ás condições do meio actual. O dia de hoje, sem o de hontem, seria um enigma impenetravel. (12)

O homem mundial da actualidade é o mesmo homem do grupo patriarchal preclassico, transformado atravéz do tempo e do espaço.

A sociedade mundial de hoje é a mesma sociedacle oriental, igualmente transformada atravéz do tempo e do espaço.

O direito que os acompanha é tambem o mesmo direíto primitivo, transformado e readaptado.

(12) Meus Ensaios citados, $\$ \$$ e paginas índicadas no indice alphabetico, $v$. presente. 